\title{
HOXB13 and TFF3 can contribute to the prognostic stratification of prostate adenocarcinoma
}

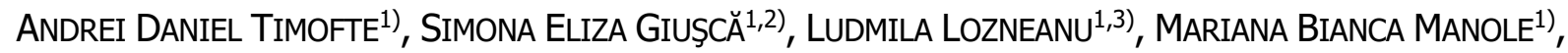

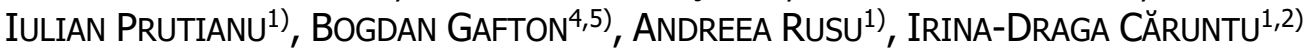 \\ 1) Department of Morphofunctional Sciences I, Grigore T. Popa University of Medicine and Pharmacy, Iaşi, Romania \\ 2) Department of Pathology, Dr. C. I. Parhon University Hospital, Iaşi, Romania \\ 3) Department of Pathology, Sf. Spiridon Emergency County Hospital, Iaşi, Romania \\ 4) III' Medical Department - Medical Oncology - Radiotherapy, Grigore T. Popa University of Medicine and Pharmacy, \\ Iaşi, Romania \\ 5) Clinic of Oncology, Regional Institute of Oncology, Iaşi, Romania
}

\begin{abstract}
Homeobox B13 (HOXB13) and trefoil factor 3 (TFF3) are novel candidates for the classification of prostate cancer (PC) in molecular subtypes that could predict the clinical evolution of patients. The aim of our study was to analyze the possible associations between HOXB13 and TFF3 immunohistochemical (IHC) expression in sporadic prostate adenocarcinoma (PAC), the potential prognostic value in relation to the classical clinico-pathological parameters, as well as their role in defining distinct molecular subtypes of this malignancy. The study group comprised 105 patients diagnosed with PAC who underwent radical prostatectomy. IHC exam was performed using anti-HOXB13 and antiTFF3 antibodies and a scoring system that permit the separation of the cases into two subgroups, with low and high immunoexpression, respectively. The statistical analysis evaluated the relationship between the two immunomarkers and clinico-pathological parameters. The Kaplan-Meier curves and log-rank Mantel-Cox test were used for assessing the prostate-specific antigen (PSA)-progression free survival. Four subgroups of PAC were defined based on the IHC overexpression and low immunoexpression of HOXB13 and TFF3. High HOXB13 and TFF3 immunoexpression was commonly identified in cases characterized by a Gleason score over 7, a G4 or G5 dominant pattern, a grade group of 3 or 4 and a preoperatory PSA serum level over $20 \mathrm{ng} / \mathrm{mL}$. HOXB13 overexpression was also associated with pathological tumor-node-metastasis (pTNM) stage. The subgroup with both low HOXB13 and TFF3 immunoexpression had the highest PSA-progression free interval, whereas the subgroup with high HOXB13 immunoexpression and low TFF3 immunoexpression presented the lowest rate, but no statistically significant differences were registered. Our results sustain the role of HOXB13 and TFF3 in the stratification of PAC. Further investigations in larger cohorts are imposed to validate the clinical significance of these subgroups in the diagnostic and prognostic of PAC.
\end{abstract}

Keywords: prostate adenocarcinoma, HOXB13, TFF3, Gleason score, prognostic grade group, molecular subtypes.

\section{Introduction}

Cumulative statistical data places prostate cancer (PC) as the second neoplastic cause of mortality in men, especially in developed countries. Surpassed only by lung cancer as regards to incidence, prostatic neoplasia accounts for 350000 deaths annually, representing $3.8 \%$ of cancer deaths worldwide $[1,2]$. These epidemiological parameters regarding $\mathrm{PC}$ have undergone significant changes, especially after the introduction of prostate-specific antigen (PSA) screening and prostate tissue biopsy in current medical practice. The use of PSA testing in the general population, concurring with easier access to improved medical services and increased life expectancy could explain the ascending trend of the overall incidence accompanied by a minimal decrease of the mortality rate, but also, could be responsible for overdiagnosis and overtreatment of $22 \%$ up to $67 \%$ of the newly indolent PC cases $[3,4]$. Facing this controversial screening procedure, numerous efforts have been directed in identifying novel, more precise methods of detection and improvement of patient selection in PC screening. In this regard, associating PSA testing with genomic information could bring significant benefits in risk stratification and also personalized therapy.

Using sequencing technologies, various recurrent early genomic alterations have been identified as having an important role in prostate carcinogenesis: gene fusions, somatic copy number alterations, speckle-type $\mathrm{POZ}$ protein $(S P O P)$ mutations. Based on genomic profiling, seven molecular subclasses of primary PC have been proposed [5]. The first four subclasses correspond to the erythroblast transformation specific (ETS) positive status, which implies the following ETS gene fusions: v-ets erythroblastosis virus $E 26$ oncogene homolog or ETS-related gene $(E R G)$ (subclass 1), ETS variant transcription factor 1 (ETVI) (subclass 2), ETS variant transcription factor 4 (ETV4) (subclass 3), and Friend leukemia integration 1 (Fli-1) proto-oncogene, ETS transcription factor (FLII) (subclass 4). The following three correspond to ETS negative status, associating mutations of following genes: SPOP (subclass 5), forkhead box A1 (FOXA1) (subclass 6), and isocitrate dehydrogenase nicotinamide adenine dinucleotide phosphate $\left(\mathrm{NADP}^{+}\right) 1(I D H 1)$ (subclass 7). Over $90 \%$ of $E T S$ fusion alterations in $\mathrm{PC}$ involve the transmembrane protease

This is an open-access article distributed under the terms of a Creative Commons Attribution-NonCommercial-ShareAlike 4.0 International Public License, which permits unrestricted use, adaptation, distribution and reproduction in any medium, non-commercially, provided the new creations are licensed under identical terms as the original work and the original work is properly cited. 
serine 2 (TMPRSS2):ERG, also termed TMPRSS2:ERG fusion [6], the rest being determined by other members of the ETS family. Apart from these molecular subtypes, an important percentage - almost $26 \%$ of prostatic neoplasms still remain determined by unclear molecular abnormalities. In this pursuit of fully understanding the molecular profile, numerous other genomic alterations were studied, namely phosphatase and tensin homolog $(P T E N)$, natural killer 3 (NK3) homeobox 1 (NKX3.1), myelocytomatosis protooncogene $(M Y C)$, retinoblastoma $(R B)$ protein, lymphoma/ leukemia-related factor $(L R F)$, cyclin-dependent kinase 12 (CDK12), promyelocytic leukemia zinc finger (PLZF) [7-12].

Among these genetic mutations, a rare, non-conservative, but recurrent substitution ( $p . G l y 84 G l u-G 84 E$ ) in the homeobox B13 (HOXB13) gene was observed, mainly in men with hereditary PC $[13,14]$. Since its discovery in 2012 [15], several HOXB13 mutations have been attributed a role in the intricate mechanism of prostatic carcinogenesis and have been studied for their potential to influence the tumor behavior and progression [16-20].

A novel candidate marker with a potential involvement in prostate carcinogenesis is represented by trefoil factor 3 (TFF3). Along with trefoil factor 2 (TFF2), TFF3 is included in the trefoil factor family and acts as a protective and repairing peptide secreted by the intestinal mucous epithelial cells [21]. The mechanism of promoting tumor progression is thought to interfere with the anti-apoptotic signaling, with the mitochondria-mediated apoptosis pathway and with anoikis resistance [22]. Several studies sustain the involvement of TFF3 in the development of colorectal, pancreatic and breast malignancies [23-30], and also in PC [22, 31-33].

\section{Aim}

Within this context, the study focused on the analysis of the possible associations between HOXB13 and TFF3 immunohistochemical (IHC) expression in sporadic prostate adenocarcinoma (PAC), as well as their potential prognostic value in relation to the classical clinico-pathological parameters.

\section{Patients, Materials and Methods}

\section{Patients}

The study group comprised 105 patients diagnosed with PAC who underwent radical prostatectomy within the Dr. C. I. Parhon University Hospital, Iaşi, Romania, between 2010 and 2018. The research had the approval of the Research Ethics Committee of the Grigore T. Popa University of Medicine and Pharmacy, Iaşi (No. 3345/2018).

For our retrospective research, the following medical data were documented from the patients' medical files: age; preoperative and postoperative PSA serum levels; pathological diagnosis including the Gleason score, dominant pattern, grade group; aggressive histological parameters (intracapsular and extracapsular, lymphovascular, and perineural invasion); pathological tumor-node-metastasis (pTNM) stage. The material was represented by archived paraffin blocks containing prostatic tissue. For all cases, the microscopic specimens were reassessed according to the 2016 World Health Organization (WHO) prostate grading system [34] and were attributed grade groups [35].

\section{Immunohistochemical analysis}

IHC analysis was performed on serial tissue slices of $4 \mu \mathrm{m}$ thickness cut from prostatic tissue paraffin-embedded blocks and placed on adhesive positively charged slides. The technique was carried out manually. Slides were deparaffinized using two xylene baths and rehydrated in successive decreasing alcohol baths (100\%, 90\%, 80\%, and $70 \%$ ), followed by rinsing in distilled water. Heatinduced epitope retrieval (HIER) procedure was used for unmasking the antigen by immersing the slides in TrisEthylenediaminetetraacetate (EDTA) solution ( $\mathrm{pH}$ 9) and placing them in a steamer at $97^{\circ} \mathrm{C}$, for 25 minutes. After that, the slides were cooled at room temperature (RT), rinsed in distilled water, and the endogenous peroxidases were inhibited with hydrogen peroxide for 10 minutes. Primary antibodies specific for HOXB13 - rabbit monoclonal antibody (clone EPR17371, ab201682, Abcam, Cambridge, MA, USA), 1:3000 dilution, and for TFF3 rabbit monoclonal antibody (clone EPR3974, ab108599, Abcam, Cambridge, MA, USA), 1:2000 dilution, were applied and incubation was performed overnight at $4{ }^{\circ} \mathrm{C}$. The secondary antibody (goat anti-rabbit IgG ab97051, Abcam, Cambridge, MA, USA) and the Streptavidin peroxidase were applied at RT, for 30 minutes each. After every incubation stage, the slides were washed in phosphate-buffered saline (PBS) solution, for 5 minutes. The immune reaction was developed with 3,3'-Diaminobenzidine (DAB) chromogen solution, followed by the Mayer's Hematoxylin counterstaining.

As positive control for HOXB13, we used the nuclear immunostaining of the epithelial cells of benign prostatic glands, while positive control for TFF3 consisted in cytoplasmic immunoexpression in goblet cells of large intestinal epithelia.

Negative control for both antibodies consisted in omitting the incubation with the primary antibody on PAC tissue sections; in addition, for the HOXB13 negative control, we used slides containing human brain tissue, which is a HOXB13 negative tissue.

\section{Scoring system}

HOXB13 immunoexpression was assessed as intensity (I) of nuclear staining $(0-$ negative, $1+-$ low, $2+-$ moderate, and $3+-$ high, in comparison to the nuclear immunostaining of epithelial cells of the adjacent benign prostatic glands) and percentage $(\mathrm{P})$ of positive tumor cells ( 0 - negative, 1 - less than $30 \%, 2$ - between $30-70 \%$, and 3 - more than $70 \%$ positive tumor cells). A total IHC score was determined as $\mathrm{I}+\mathrm{P}$ and ranged from 0 to 6 . The IHC score was later used to define two subgroups: low HOXB13 immunoexpression subgroup (included IHC scores from 1 to 4 ) and high HOXB13 immunoexpression subgroup (defined by an IHC score of 5 to/and 6).

The scoring system for TFF3 used the intensity (I) of cytoplasmic immunostaining $(0-$ negative, $1+-$ low, $2+-$ moderate, and $3+-$ high) combined with the percentage (P) of the positive tumor cells $(0-\leq 5 \%, 1-6-19 \%, 2-$ $20-49 \%, 3-\geq 50 \%$ ). The final IHC score ranged from 0 to 9 and was calculated as $\mathrm{I} \times \mathrm{P}$. Subsequently, this score was used to divide the cases into two subgroups: low TFF3 immunoexpression subgroup (defined by an IHC score from 1 to 5) and high TFF3 immunoexpression subgroup (characterized by an IHC score from 6 to 9). 


\section{Statistical analysis}

For the statistical analysis, Statistica version 7 (Tibco, Palo Alto, CA, USA), and Excel 2016 version 16.0 (Microsoft, Redmond, WA, USA) were used. The $\chi^{2}$ (chisquared) test was applied for studying associations between HOXB13 and TFF3 immunoexpression and clinicopathological variables. Kaplan-Meier curves and logrank Mantel-Cox test were used for assessing the PSAprogression free survival (biochemical recurrence free survival); $p$-values $\leq 0.05$ were considered as statistically significant.

\section{口 Results}

\section{Clinico-pathological characteristics}

The age at onset for the patients included in the study ranged between 51 and 77 years old, with a median of 66 years old.

According to the Gleason score, patients were included in the grade groups, as follows: $32(30.47 \%)$ patients in grade group 1 (six patients with Gleason score 5 and 26 patients with Gleason score 6$), 48(45.71 \%)$ patients in grade group 2 with Gleason score $7(=3+4)$, eight $(7.61 \%)$ patients in grade group 3 with Gleason score $7(=4+3)$, nine $(8.57 \%)$ patients in grade group 4 [from which one patient with Gleason score $8(=3+5)$, one patient with Gleason score $8(=5+3)$ and seven patients with Gleason score $8(=4+4)$ ], eight $(7.61 \%)$ patients in grade group 5, all with Gleason score $9(=4+5)$. The dominant patterns were Gleason pattern 3 in $81(77.41 \%)$ cases, Gleason pattern 4 in $23(21.9 \%)$ cases and Gleason pattern 5 in one case $(0.95 \%)$.

The invasion in prostate capsule, both at intracapsular and extracapsular level, was present in 94 (89.52\%) cases and absent in the other $11(10.48 \%)$ cases. The perineural invasion was identified in $79(75.24 \%)$ cases, missing in $26(24.76 \%)$ cases, whereas tumor emboli that confirm the lymphovascular invasion were found in $18(17.14 \%)$ cases, without evidence in the rest of $87(82.86 \%)$ cases.

The tumor stage in accordance with the primary tumor
(pT) criteria of WHO Classification was pT2 in $74(70.48 \%)$ cases, and pT3 in 31 (29.52\%) cases.

The preoperative PSA serum levels were available for 94 out of 105 patients, presenting a high degree of variability (minimum value of $2.15 \mathrm{ng} / \mathrm{mL}$ and maximum of $98 \mathrm{ng} / \mathrm{mL}$ ), with a median value of $10.9 \mathrm{ng} / \mathrm{mL}$ and mean value of $14.22 \mathrm{ng} / \mathrm{mL}$.

Of the 105 cases that underwent radical prostatectomy, only 72 cases were followed postoperatively for PSA progression, almost half of them (35 cases $-48.61 \%$ ) showing biochemical recurrence (PSA $\geq 0.2 \mathrm{ng} / \mathrm{mL}$ ).

\section{HOXB13 immunoexpression}

For all 105 cases, positive immunostaining was limited to the luminal secretory cells of the benign prostatic glands, thus for each case, HOXB13 immunostaining in tumor glands was assessed in comparison to the intensity of the benign adjacent glands, and was considered weak in $18(17.14 \%)$ cases with IHC scores of $1-2$, moderate in $56(53.33 \%)$ cases with IHC scores of $3-4$, strong in $30(28.57 \%)$ cases with IHC score of 5 , and a single case was negative. The IHC scores were used to form the two subgroups: low HOXB13 immunoexpression subgroup comprising $75(71.42 \%)$ cases and high HOXB13 immunoexpression subgroup including 30 (28.57\%) cases. Representative images of HOXB13 immunostaining are depicted in Figures 1-4.

\section{TFF3 immunoexpression}

Regarding TFF3 immunostaining of the analyzed tumor prostatic tissue, we assessed $24(22.85 \%)$ cases as being negative and weak immunostained, with IHC score of $1-2,37(35.23 \%)$ cases had moderate immunoexpression with IHC score of 3-5, and $44(41.9 \%)$ cases showed strong immunostaining with IHC score of 6-9. Applying the IHC score, we defined two subgroups: low TFF3 immunoexpression subgroup represented by 61 (58.1\%) cases and high TFF3 immunoexpression subgroup composed of $44(41.9 \%)$ cases. Different aspects of TFF3 immunostaining are illustrated in Figures 5-8.

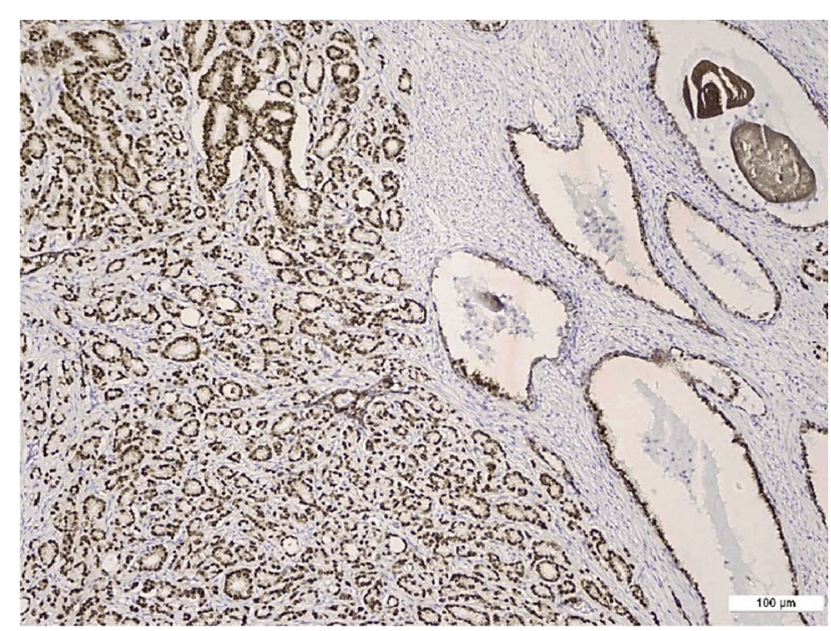

Figure 1 - HOXB13 - high and moderate nuclear immunostaining in PAC, Gleason pattern 3. AntiHOXB13 antibody immunostaining, $\times 100$. HOXB13: Homeobox B13; PAC: Prostate adenocarcinoma.

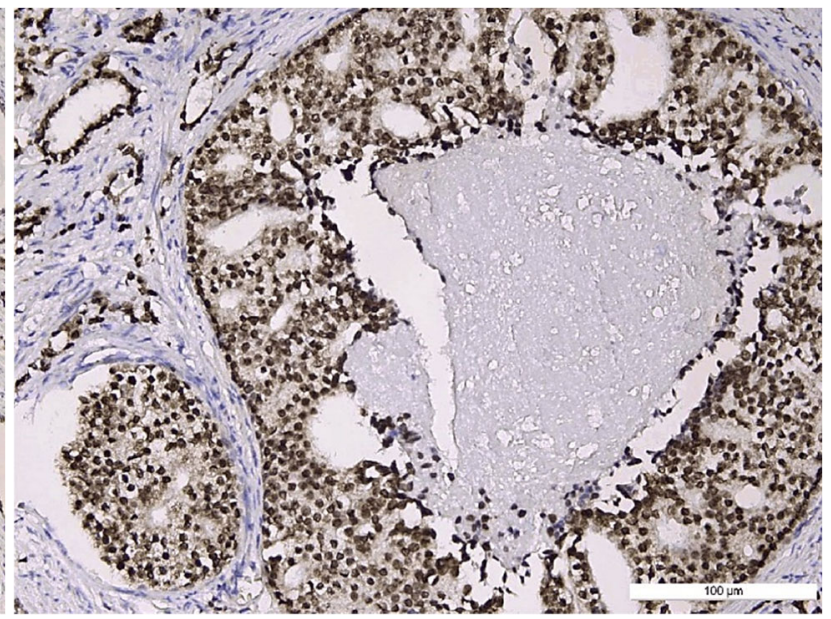

Figure 2 - HOXB13 - high nuclear immunostaining in $P A C$, Gleason pattern 5, cribriform glands with comedonecrosis. Anti-HOXB13 antibody immunostaining, $\times 200$. HOXB13: Homeobox B13; PAC: Prostate adenocarcinoma. 


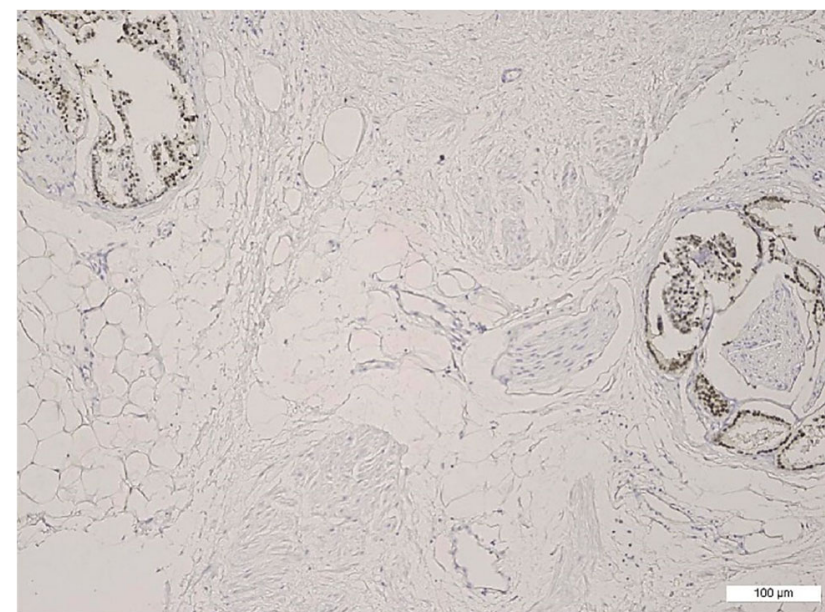

Figure 3 - HOXB13 - moderate nuclear immunostaining in the tumor glands - PAC with extracapsular extension and perineural invasion. Anti-HOXB13 antibody immunostaining, ×100. HOXB13: Homeobox B13; PAC: Prostate adenocarcinoma.

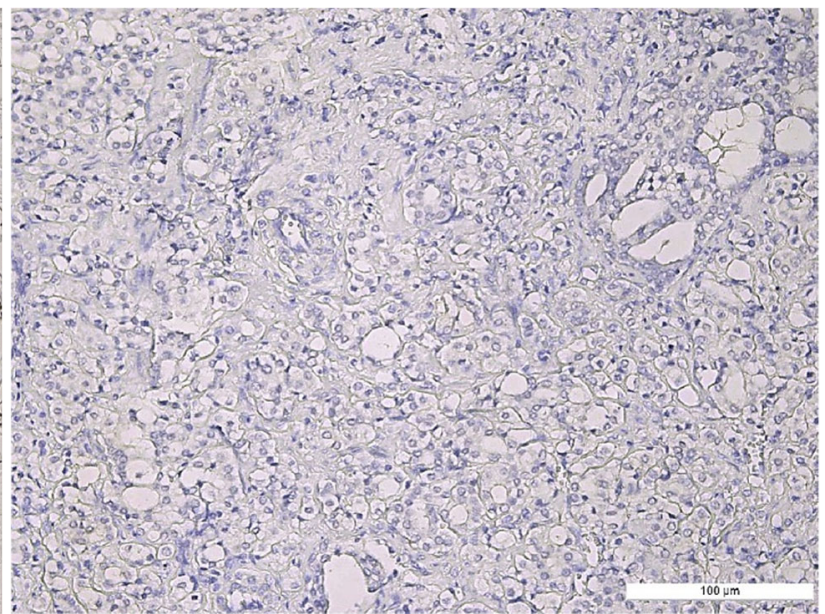

Figure 4-HOXB13 - negative immunoreaction in PAC, dominant Gleason pattern 4. Anti-HOXB13 antibody immunostaining, $\times 200$. HOXB13: Homeobox B13; PAC: Prostate adenocarcinoma.

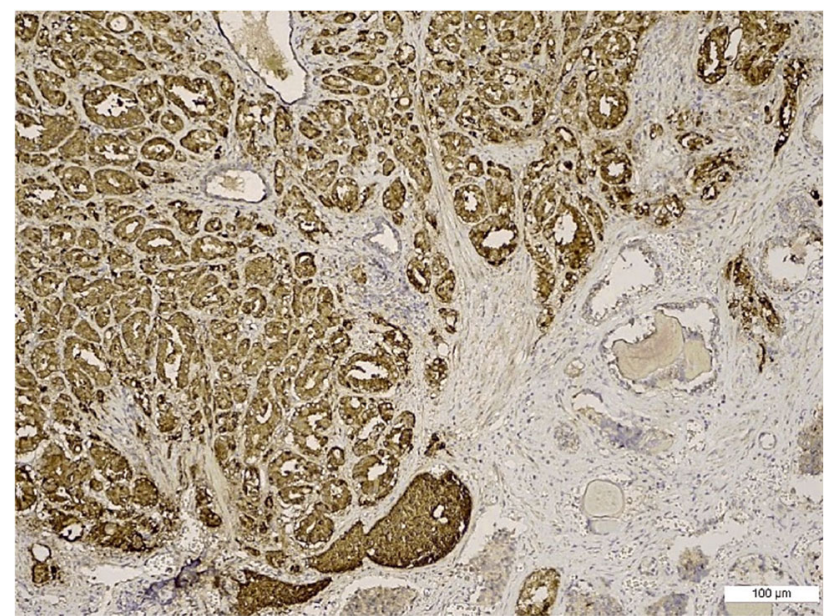

Figure 5-TFF3 - high cytoplasmic immunostaining in PAC, dominant Gleason pattern 3. Anti-TFF3 antibody immunostaining, $\times 100$. PAC: Prostate adenocarcinoma; TFF3: Trefoil factor 3.

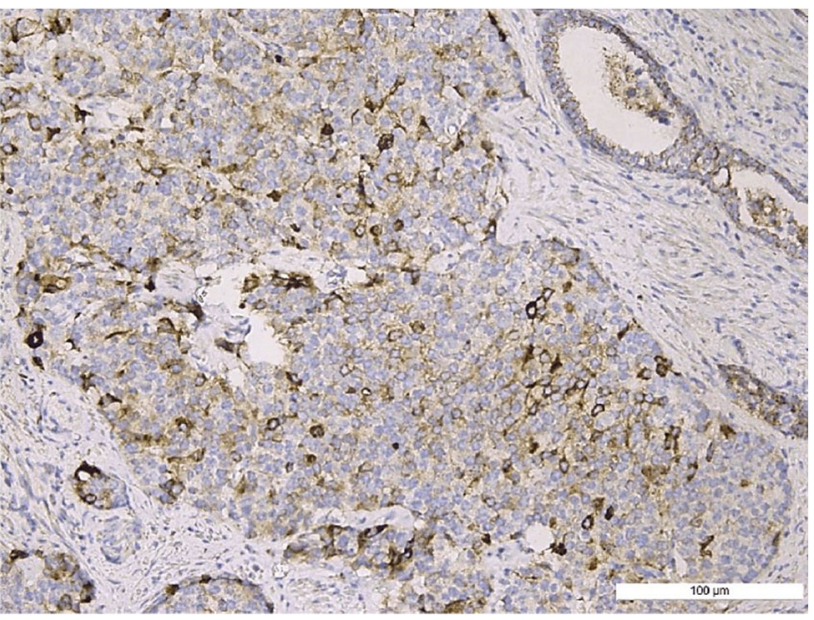

Figure 7 - TFF3 - heterogenous cytoplasmic immunostaining in PAC, Gleason pattern 5, solid nests. AntiTFF3 antibody immunostaining, $\times 200$. PAC: Prostate adenocarcinoma; TFF3: Trefoil factor 3.

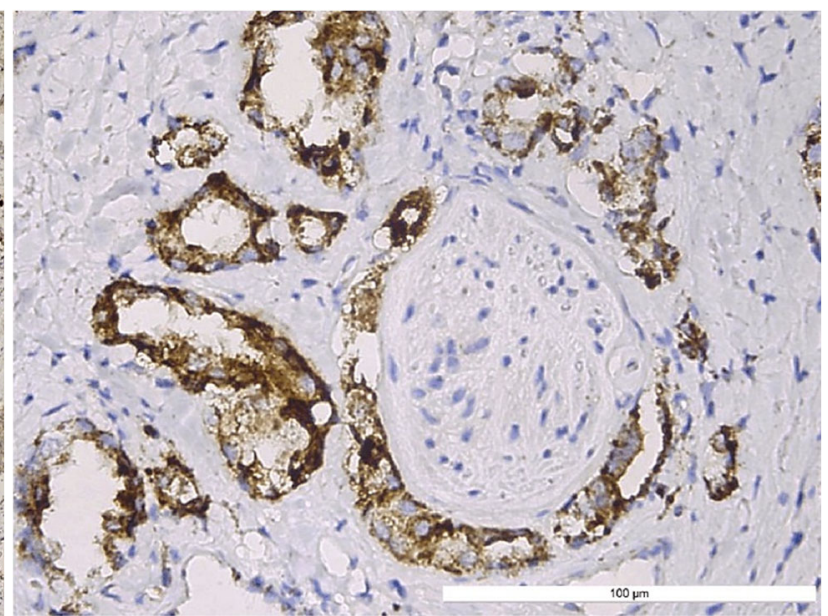

Figure 6-TFF3 - positive cytoplasmic immunoexpression in tumor glands - perineural invasion in PAC. Anti-TFF3 antibody immunostaining, $\times 400$. PAC: Prostate adenocarcinoma; TFF3: Trefoil factor 3.

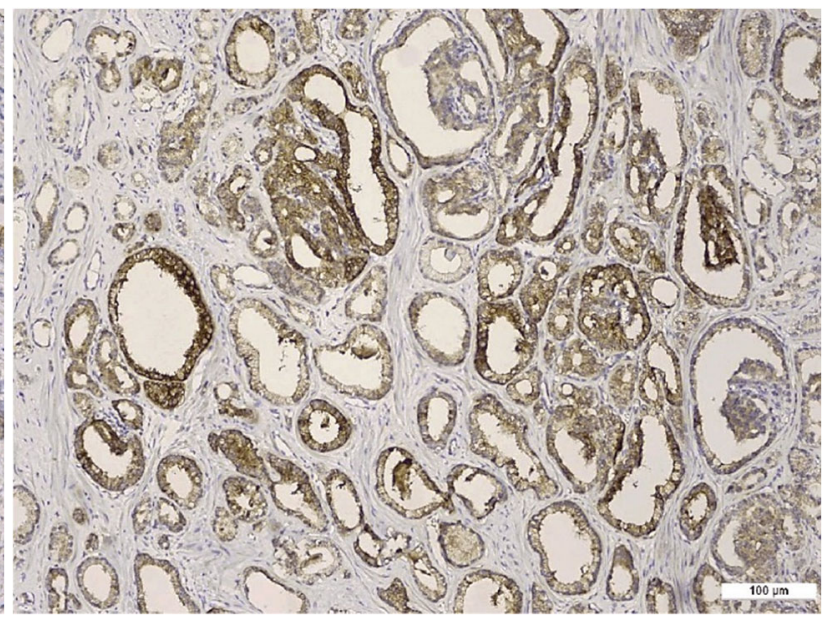

Figure 8 - TFF3 - low and moderate cytoplasmic immunostaining in PAC, Gleason pattern 3 and $4-$ glomeruloid structures. Anti-TFF3 antibody immunostaining, $\times 100$. PAC: Prostate adenocarcinoma; TFF3: Trefoil factor 3 . 


\section{Correlation between HOXB13 and TFF3 immunoexpression}

Based on the IHC profile, four different subgroups were defined, as follows: subgroup 1, with high immunoexpression of HOXB13 and TFF3 - 27 (25.71\%) cases; subgroup 2, with high HOXB13 immunoexpression and low TFF3 immunoexpression - 3 (2.85\%) cases; subgroup 3, with high TFF3 immunoexpression and low HOXB13 immunoexpression - 17 (16.19\%) cases; subgroup 4, with both HOXB13 and TFF3 low immunoexpression - 58 $(55.23 \%)$ cases. The statistical analysis revealed a significant relation between HOXB13 and TFF3 tissular immunoexpression $(p<0.0001)$.

High HOXB13 immunoexpression was found in 27 of $44(61.36 \%)$ cases of PAC with high TFF3 immuno- expression, and only in three of 61 (4.91\%) cases exhibiting low TFF3 immunoexpression.

\section{Correlation between HOXB13 and TFF3 immunoexpression and clinico-pathological parameters}

The statistical analysis showed that the high HOXB13 immunoexpression was significantly linked with higher Gleason scores and dominant pattern, higher grade group, tumor stage and also higher preoperative PSA levels, but did not correlate with the age of onset. Also, strong HOXB13 immunoexpression was significantly associated with aggressive features like perineural and lymphovascular invasion, but not with tumor capsular involvement/extension (Table 1).

Table 1 - Relationship between HOXB13 and TFF3 immunoexpressions and clinico-pathological characteristics

\begin{tabular}{|c|c|c|c|c|c|c|c|c|c|}
\hline \multirow[b]{2}{*}{$\begin{array}{c}\text { Clinico-pathological } \\
\text { parameters }\end{array}$} & \multirow[b]{2}{*}{$\#$} & \multicolumn{2}{|c|}{ HOXB13 } & \multirow[b]{2}{*}{$x^{2}$} & \multirow[b]{2}{*}{$p$-value } & \multicolumn{2}{|c|}{ TFF3 } & \multirow[b]{2}{*}{$x^{2}$} & \multirow[b]{2}{*}{$p$-value } \\
\hline & & $\begin{array}{c}\text { Low immuno- } \\
\text { expression } \\
\#, \%\end{array}$ & $\begin{array}{c}\text { High immuno- } \\
\text { expression } \\
\#, \%\end{array}$ & & & $\begin{array}{c}\text { Low immuno- } \\
\text { expression } \\
\#, \%\end{array}$ & $\begin{array}{c}\text { High immuno- } \\
\text { expression } \\
\#, \%\end{array}$ & & \\
\hline Patient age [years] & & & & 1.38 & 0.24 & & & 0.17 & 0.68 \\
\hline$\leq 65$ & 50 & $33(44 \%)$ & $17(56.66 \%)$ & & & $28(45.90 \%)$ & $22(50 \%)$ & & \\
\hline$>65$ & 55 & $42(56 \%)$ & $13(43.34 \%)$ & & & $33(54.10 \%)$ & $22(50 \%)$ & & \\
\hline \multicolumn{4}{|c|}{ Preoperatory PSA levels [ng/mL] } & 13.14 & 0.0013 & & & 6.2 & 0.044 \\
\hline$\leq 10.0$ & 44 & $37(55.23 \%)$ & $7(25.92 \%)$ & & & $30(55.55 \%)$ & $14(35 \%)$ & & \\
\hline $10.1-20.0$ & 30 & $22(32.83 \%)$ & $8(29.62 \%)$ & & & $17(31.48 \%)$ & $13(32.5 \%)$ & & \\
\hline$>20$ & 20 & $8(11.94 \%)$ & $12(44.44 \%)$ & & & $7(12.96 \%)$ & $13(32.5 \%)$ & & \\
\hline No data & 11 & & & & & & & & \\
\hline Gleason score & & & & 11.23 & 0.0008 & & & 10.14 & 0.0014 \\
\hline$<7$ & 32 & $30(40 \%)$ & $2(6.67 \%)$ & & & $26(42.62 \%)$ & $6(13.64 \%)$ & & \\
\hline$\geq 7$ & 73 & $45(60 \%)$ & $28(93.33 \%)$ & & & $35(57.38 \%)$ & $38(86.36 \%)$ & & \\
\hline Dominant pattern & & & & 32.86 & 0.00001 & & & 14.00 & 0.00018 \\
\hline$\leq \mathrm{G} 3$ & 81 & $69(92 \%)$ & $12(40 \%)$ & & & $55(90.16 \%)$ & $26(59.09 \%)$ & & \\
\hline G4, G5 & 24 & $6(8 \%)$ & $18(60 \%)$ & & & $6(13.64 \%)$ & $18(40.91 \%)$ & & \\
\hline ISUP grade group & & & & 30.32 & 0.00001 & & & 12.21 & 0.0004 \\
\hline $1-2$ & 80 & $68(90.67 \%)$ & $12(40 \%)$ & & & $54(88.52 \%)$ & $26(59.09 \%)$ & & \\
\hline $3-4-5$ & 25 & $7(9.33 \%)$ & $18(60 \%)$ & & & $7(11.48 \%)$ & $18(40.91 \%)$ & & \\
\hline Capsular invasion & & & & 0.21 & 0.65 & & & 0.51 & 0.47 \\
\hline Present & 94 & $66(88 \%)$ & $28(93.33 \%)$ & & & $53(86.89 \%)$ & $41(93.18 \%)$ & & \\
\hline Absent & 11 & $9(12 \%)$ & $2(6.67 \%)$ & & & $8(3.11 \%)$ & $3(6.82 \%)$ & & \\
\hline Perineural invasion & & & & 3.87 & 0.049 & & & 3.19 & 0.07 \\
\hline Present & 79 & $52(69.33 \%)$ & $27(90 \%)$ & & & $42(68.85 \%)$ & $37(84.09 \%)$ & & \\
\hline Absent & 26 & $23(30.67 \%)$ & $3(10 \%)$ & & & $19(31.15 \%)$ & $7(15.91 \%)$ & & \\
\hline Lymphovascular invasio & & & & 7.75 & 0.005 & & & 3.29 & 0.07 \\
\hline Present & 18 & $8(10.67 \%)$ & $10(33.33 \%)$ & & & $7(11.48 \%)$ & $11(25 \%)$ & & \\
\hline Absent & 87 & 67 (89.33\%) & $20(66.67 \%)$ & & & $54(88.52 \%)$ & $33(75 \%)$ & & \\
\hline$\overline{p T N M}$ stage & & & & 3.85 & 0.049 & & & 3.02 & 0.08 \\
\hline $\mathrm{T} 2$ & 74 & $57(76 \%)$ & $17(56.67 \%)$ & & & 47 (77.05\%) & 27 (61.36\%) & & \\
\hline T3-T4 & 31 & $18(24 \%)$ & $13(43.33 \%)$ & & & $14(22.95 \%)$ & $17(38.64 \%)$ & & \\
\hline
\end{tabular}

\#: No. of cases; \%: Percent of cases; $X^{2}$ : Chi-squared test; HOXB13: Homeobox B13; ISUP: International Society of Urological Pathology; PSA: Prostate-specific antigen; pTNM: Pathological tumor-node-metastasis; TFF3: Trefoil factor 3.

As for TFF3 overexpression, the statistical data indicated a strong association with higher Gleason score and dominant pattern, higher grade groups, higher serum preoperative levels of PSA, but there was no significant correlation with age of onset and pTMN staging. Regarding the aggressive features, TFF3 immunoexpression did not correlate with capsular involvement, nor with perineural and lymphovascular invasion (Table 1).

\section{Correlation of HOXB13 and TFF3 overexpression with biochemical PSA recurrence}

Biochemical recurrence was regarded as an indicator of disease progression and consisted of the first increase of serum PSA levels higher than $0.20 \mathrm{ng} / \mathrm{mL}$, after radical prostatectomy. In our study group, $48.61 \%(35 / 72)$ of the 
followed patients presented biochemical recurrence. The Kaplan-Meier curve showed that HOXB13 overexpression was associated with a decrease in PSA-progression free survival, without significant statistically difference (logrank Mantel-Cox, $p=0.768$ ) (Figure 9). Similar results were obtained for TFF3 high immunoexpression (log-rank Mantel-Cox, $p=0.909$ ) (Figure 10).

The correlation between the four subgroups defined in accordance with the HOXB13-TFF3 immunoprofile and biochemical recurrence showed that subgroup 4, with both low HOXB13 and TFF3 immunoexpression had the highest PSA-progression free interval, whereas subgroup 2, with high HOXB13 immunoexpression and low TFF3 immunoexpression presented the lowest rate, but no statistically significant differences were registered $(\log$ rank Mantel-Cox, $p=0.759$ ) (Figure 11).

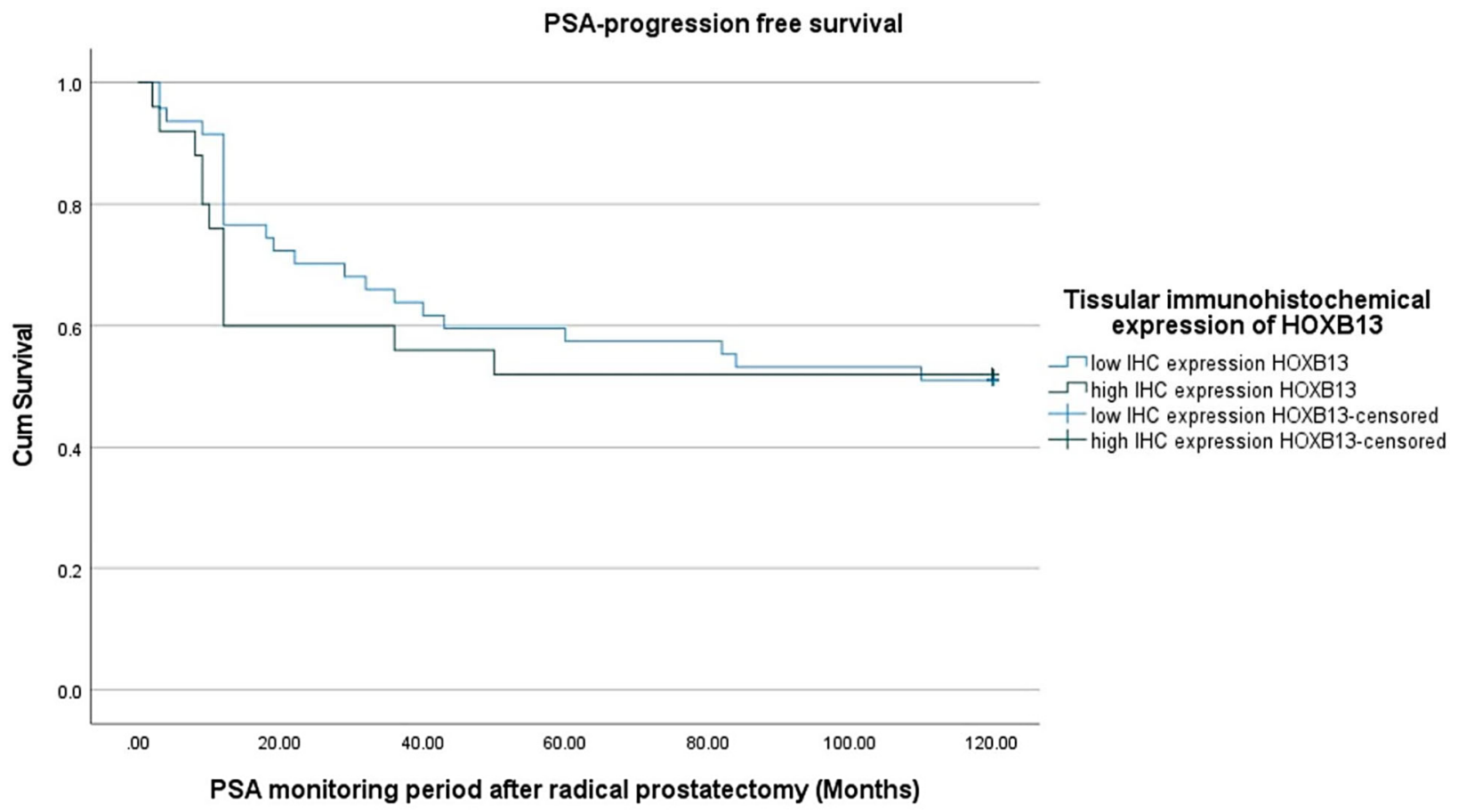

Figure 9 - Kaplan-Meier curve for PSA-progression free survival in relation to HOXB13 immunoexpression. HOXB13: Homeobox B13; IHC: Immunohistochemical; PSA: Prostate-specific antigen.

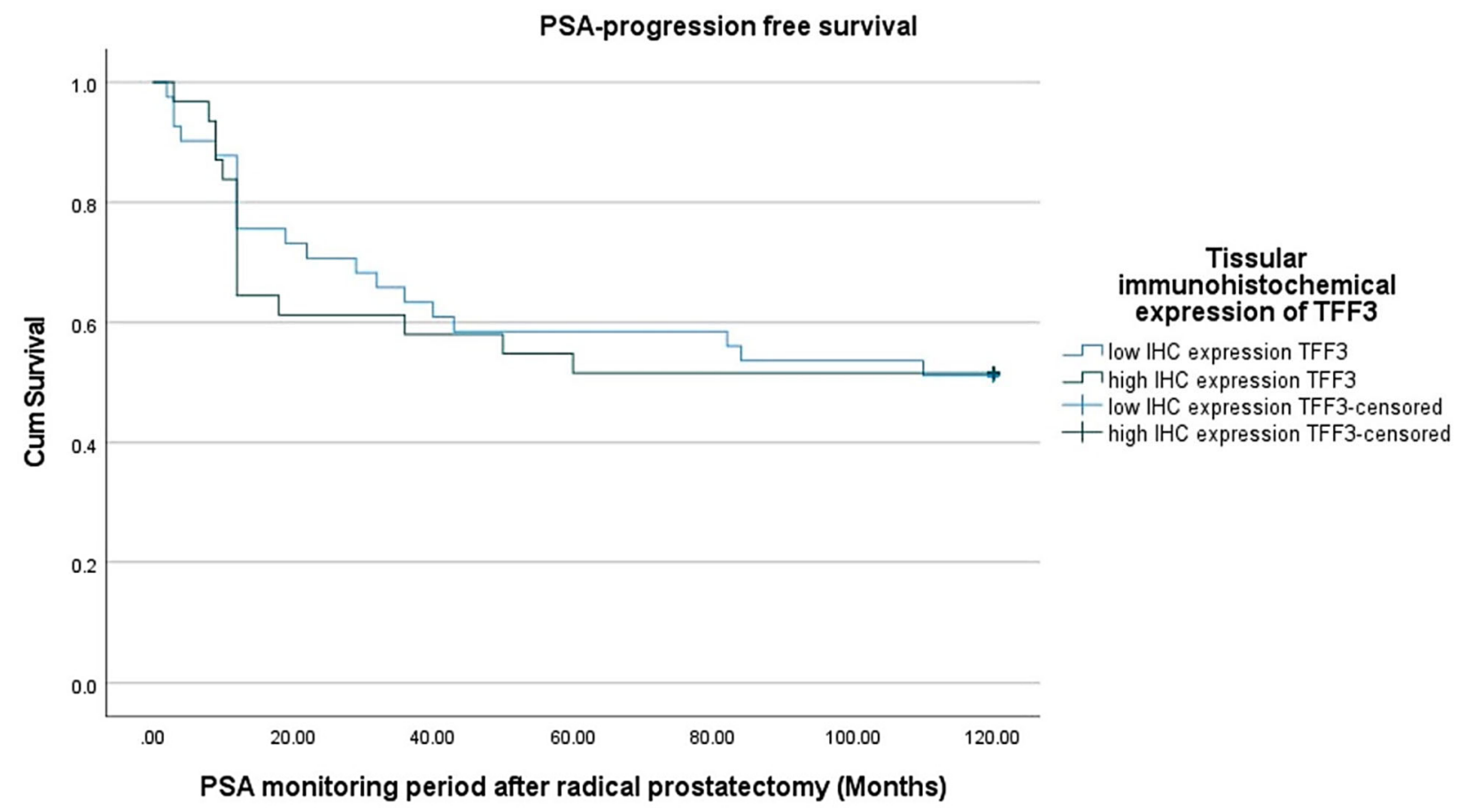

Figure 10 - Kaplan-Meier curve for PSA-progression free survival in relation to TFF3 immunoexpression. IHC: Immunohistochemical; PSA: Prostate-specific antigen; TFF3: Trefoil factor 3. 


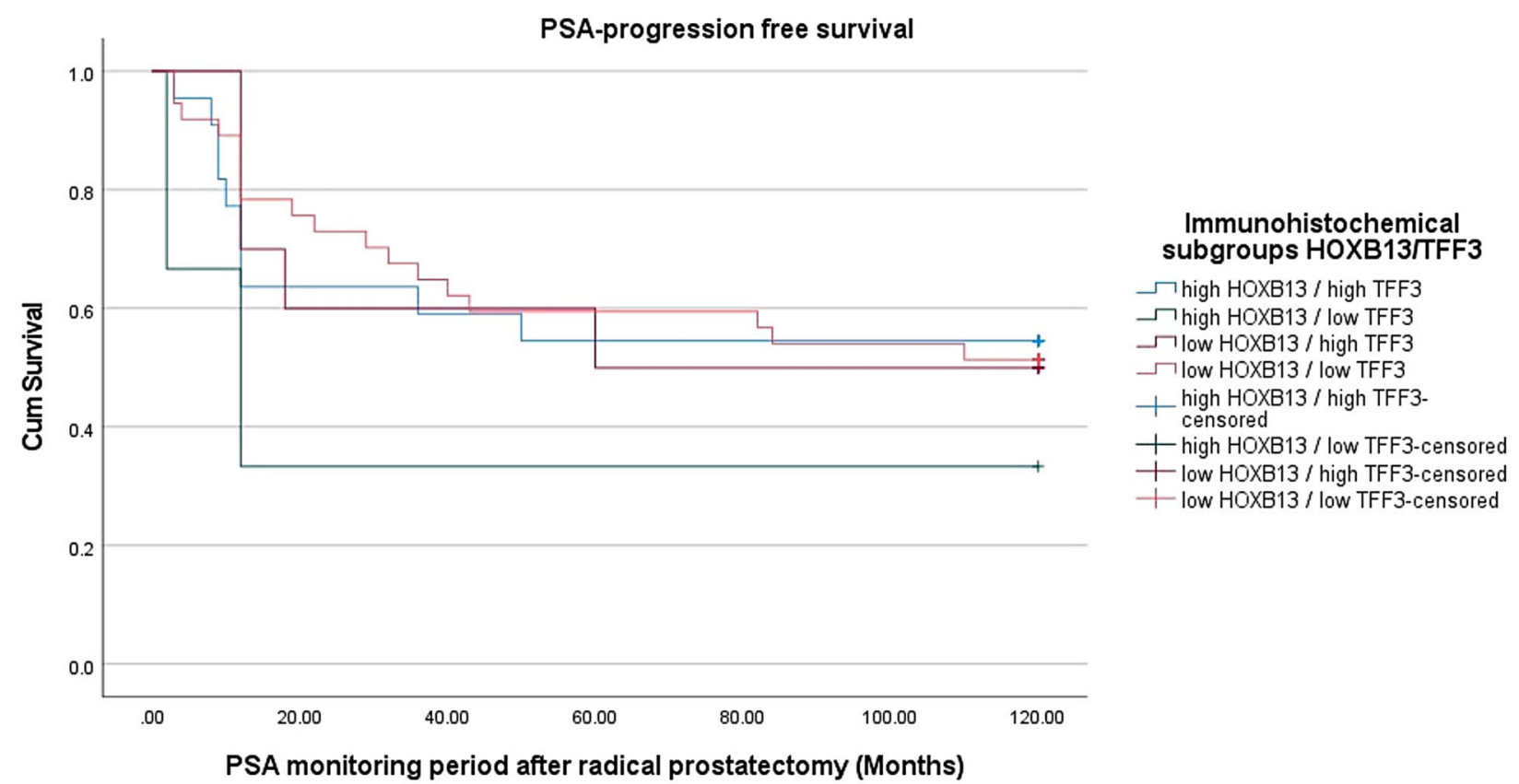

Figure 11 - Kaplan-Meier curve for PSA-progression free survival in relation to HOXB13-TFF3 subgroups. HOXB13: Homeobox B13; IHC: Immunohistochemical; PSA: Prostate-specific antigen; TFF3: Trefoil factor 3.

\section{Discussions}

Over the last decade, numerous efforts have been directed into unraveling the intrinsic mechanisms involved in prostatic carcinogenesis, aiming at a better understanding of the heterogeneity of this disease in terms of histology, behavior, and prognosis. In this regard, PC is integrated in the current trend of changing the operational classifications, in the sense of refining them, by identifying and certifying some molecular subtypes. The classification of PC in molecular subtypes, together with the prognostic and diagnostic value of the various biomarkers currently under study, could have a critical role in predicting the clinical evolution, as well as in developing a targeted, individualized therapy. Therefore, the evaluation of the IHC expression of some of these molecular/genetic markers can be of great use in differentiating indolent prostate tumors from those with a potentially aggressive evolution, having applicability in establishing an early individualized therapy based on stratification protocols.

Within this context, our work, focused on the HOXB13 and TFF3 immunoexpression in PAC, is aiming to analyze the possible association of these two markers with the classical clinico-pathological variables, and the potential prognostic value based on the correlations with disease recurrence, assessed by the PSA-progression free survival.

Our study revealed an important heterogeneity of both HOXB13 and TFF3 IHC immunoexpression in PAC.

\section{HOXB13 profile}

Since it was firstly described by Zeltser et al. in 1996, as being the last discovered homeobox gene [36], multiple studies have been conducted in order to elucidate $H O X B 13$ functions in prostate development and also in carcinogenesis [15, 37-39]. Despite its established role as transcriptional modulator of the androgen independent and androgen responsive genes in prostate development [40], HOXB13's part in prostate carcinogenesis still remains controversial, being regarded as both an oncogene and a tumor suppressor gene $[15,37]$. In addition, the pro-oncogenic mechanisms caused by $H O X B 13$ mutations have not yet been fully elucidated [41-43]. The review of the literature studies shows a HOXB13 overexpression especially in hereditary prostatic carcinomas characterized by $G 48 E$ mutations $[15,44]$.

The G84E predisposing mutation involving the $H O X B 13$ gene has an estimated prevalence of $0.1-0.6 \%$ in the male population and is accompanied by an increased risk for PC (up to 3-5 fold), even at younger ages, as opposed to non-carrier males $[44,45]$. In the last decade, apart from $G 84 E$, the incidence of different germline $H O X B 13$ mutational variants $(Y 88 D, L 144 P, G 216 C, R 229 G$, $G 135 E, R 217 C, A 128 D / F 248 L)$ with direct involvement in hereditary transmission of prostatic neoplasia has been assessed by extensive genetic studies [15-17, 46]. However, IHC quantification of $\mathrm{HOXB13}$ expression and its possible correlation to different parameters (tumor phenotype, biochemical recurrence, androgen receptivity, PSA levels) and to other biomarkers of interest (i.e., PTEN, ERG) still requires investigation and confirmation. Consequently, the characteristics of HOXB13 overexpressed prostate neoplasms are incompletely clarified [47].

In our study, the HOXB13 assessment showed weak expression in $18(17.14 \%)$ cases, moderate immunoreaction in $56(53.33 \%)$ cases, strong immunostaining in $30(28.57 \%)$ cases, a single case $(0.95 \%)$ being negative. By applying the semi-quantitative scoring system, $75(71.42 \%)$ cases were classified in the low expression subgroup, the other $30(28.57 \%)$ cases belonging to the high immunoexpression subgroup.

Our results complement the extremely discordant data on HOXB13 immunoexpression in PAC. Thus, in contrast to our findings, in a larger population study using tissue microarray containing more than $12400 \mathrm{PCs}, \mathrm{HOXB} 13$ immunostaining was predominantly negative $-48.3 \%$ of cases; weak and moderate immunoexpression were present 
in $22.3 \%$, respectively $19.7 \%$ of cases, and only $9.6 \%$ of cases were evaluated as strong [47]. On the other hand, a study limited to only 400 cases reported a 100\% HOXB13 strong IHC expression [48]. Another paper analyzing 56 tissue samples from androgen-dependent and independent PAC demonstrated moderate and strong expression in only $30 \%$ of the 44 androgen-dependent cases, and in $83 \%$ of the other 12 androgen-refractory cases [39]. A recent study focused on the comparative analysis of HOXB13 in benign prostatic hyperplasia, $\mathrm{PAC}$, and prostate neuroendocrine tumors; HOXB13 was consistently expressed in hyperplasia (26/28 cases), while in PAC the immunoexpression was stronger for Gleason score $\geq 7$, with statistically significant differences for Gleason score 9 and 10; HOXB13 was completely absent in neuroendocrine tumors [49].

Joining these discordant results, our data sustain the idea that HOXB13 expression is not homogeneous and static, but rather heterogeneous and dynamic during the course of neoplastic disease. HOXB13 can be either suppressed in tumors that lose their normal prostate identity by acquiring a malign phenotype, or overexpressed due to intrinsic molecular mechanisms that make tumor transformation and growth possible, sometimes even in the absence of androgenic stimulation. Nonetheless, we must take into consideration that the large variations in reporting the IHC positivity rate of $\mathrm{HOXB13}$ could be explained using different IHC protocols or IHC scoring systems.

Regarding the clinico-pathological variables, our study showed no statistically significant correlation of HOXB13 immunoexpression with the age of onset. Similar results are supported in literature [50], but it is worth mentioning that several genetic studies conducted on large populations confirm the association of HOXB13 germline mutations with increased odds of early prostatic cancer onset, as well as increased likelihood of having a family history of PC $[15,18,19]$. A possible explanation for these discrepancies could be the fact that in sporadic PC, HOXB13 is more likely to be amplified than mutated, and thus prostate tumor initiation could be prolonged, rather than accelerated as seen in $H O X B 13$ germline mutation carriers [51].

Our results sustained the relationship between HOXB13 high immunoexpression and Gleason score $(p=0.0008)$, prognostic grade group $(p=0.00001)$, dominant pattern $(p=0.00001)$, tumor stage $(p=0.049)$, perineural invasion $(p=0.049)$ and lymphovascular invasion $(p=0.005)$, but although the majority of PAC with high HOXB13 immunoexpression presented capsular involvement (28/30), the statistical threshold was not reached $(p=0.65)$. The association between HOXB13 overexpression and higher prognostic grade groups is supported by a recent research in the field of genetics [52]. Using genomic-scale association studies on tissue samples from more than 6000 radical prostatectomies, the authors found an increase in HOXB13 messenger ribonucleic acid (mRNA) expression relative to higher International Society of Urological Pathology (ISUP) prognostic grading groups [52]. The same overexpression was observed in tumors with clinical evolution to metastasis, suggesting a potential prognostic role of the HOXB13 immunomarker [52]. Thus, our data corroborate with other studies reflecting a relevant role of HOXB13 in prostate carcinogenesis and its involvement in the development of a more aggressive tumor phenotype [47, 49].

The HOXB13 immunoexpression was statistically linked with the preoperative PSA serum levels, and proved consistent with recent reports [53], while several studies support the role of HOXB13 as an androgen receptor (AR) repressor in modulating the AR signaling pathway and subsequently the growth regulation of tumor cells clinically reflected in lower serum expression of PSA $[38,40]$. A possible explanation for our results could be represented by the theory that HOXB13 overexpression, even in the absence of androgen - as seen in androgenrefractory PAC, still promotes, via alternative signaling, a positive growth signal on tumor cells, reflected in higher levels of serum PSA [39, 54].

However, the HOXB13 immunoexpression was not significantly correlated with the postoperatory PSA serum level, as marker for PSA-progression free survival, but the Kaplan-Meier curve revealed a tendency of association with a reduction of the interval of biochemical recurrence. Few larger studies proved this relationship, thus considering HOXB13 as a potential prognostic factor $[47,55]$.

\section{TFF3 profile}

Several studies have focused on the involvement of TFF3 in the carcinogenetic mechanism, supporting a possible role in the development of colorectal, pancreatic, breast cancer [26-29], and prostatic neoplasia [22, 31-33]. Recent data aims to identify the contribution of TFF3 in the large cascade of prostate tumorigenesis [22]. Experimental evidence revealed the role of TFF3 in the cellular cycle regulation [56], a down-regulation of TFF3 gene leading to a significant decrease in tumor cell growth and migration [22]; these findings support the TFF3 involvement in prostate dissemination and metastasis [22]. TFF3 overexpression has been observed in tumor prostate cells under conditions of hypomethylation of the TFF3-promoting molecular substrate [57]. However, the results obtained so far do not fully explain the functional and biological mechanism of TFF3 in the development of PAC. Consequently, our study brings data that supplements the current framework of knowledge on the relationship between TFF3 and prostate tumor phenotype.

In our research, 24 (22.85\%) cases presented negative and weak staining, $37(35.23 \%)$ cases - a moderate immunostaining, while $44(41.9 \%)$ cases showed strong intensity of cytoplasmic staining, in comparison with normal prostatic cells. By applying the semi-quantitative scoring system, $61(58.1 \%)$ cases were allocated to the low immunoexpression subgroup, and the other 44 (41.9\%) cases were classified in the high immunoexpression subgroup.

Thus, our results are consistent with previous data from two studies that reported TFF3 positivity in 47\% [31], and $42 \%$ [32] of cases, whereas another research found TFF3 expression in only $31 \%$ of a set of 76 prostatic biopsies [58]. These results simply identify a subset of prostatic carcinomas with overexpression of TFF3, but further investigation is needed to link the IHC profile to 
a potential role of TFF3 in facilitating prostate carcinogenesis and progression. It is worth noticing that a more recent study evaluated the prognostic potential of TFF3 in combination with two markers, ERG and serine peptidase inhibitor Kazal type 1 (SPINK1), and consequently defined two new molecular subsets of TFF3 positive prostatic cancer, based on the evidence that TFF3 and ERG protein expression are inversely linked, whereas SPINK1 is fully overexpressed when TFF3 is present [33].

Our work indicated a strong association of TFF3 high immunoexpression with higher dominant pattern ( $p=0.00018)$, Gleason score $(p=0.0014)$, and grade groups ( $p=0.0004)$. As opposed to our findings, other studies showed a less frequently TFF3 immunopositivity in advanced Gleason grade groups, and no correlation with Gleason score [32, 59] and grade group [59]. We also noticed no significant correlations between TFF3 and other clinico-pathological parameters - namely age of onset, tumor stage, capsular involvement, perineural and lymphovascular invasion. These results were similar to several published papers $[31,32,59]$. In terms of PSA values, a significant correlation between high TFF3 immunoexpression and high preoperative PSA levels was also found ( $p=0.044$ ), according to the elevated TFF3 tissue immunoexpression and serum level confirmed in patients with an aggressive phenotype [31] concomitant with bone metastases [60].

These various results suggest the shaping of a TTF3 IHC profile in non-homogeneous PACs, which seems to be in discrepancy with the intracellular molecular profile of TFF3 mRNA - low levels of TFF3 mRNA being observed more frequently in tumor cells from adenocarcinomas with high Gleason score, advanced tumor stage and with biochemical recurrence [61]. Differences between protein expression and transcriptional levels in prostate tumor cells could be attributed to different methods of evaluating TFF3 immunoexpression in the studied samples: gene sequencing (a quantitative, dynamic method) versus IHC quantification (a static, semi-quantitative method). Also, the level of TFF3 mRNA could vary due to the mechanisms of post-transcriptional regulation of TFF3 and the loss of TFF3 in the extracellular space, thus not reflecting the intracytoplasmic protein expression of TFF3 [57].

As in the case of HOXB13 evaluation, the statistical analysis revealed no statistically significant correlation between the TFF3 immunoexpression and postoperatory PSA serum level.

These contradictory findings strengthen the necessity of a better investigation and understanding regarding the subjacent biological mechanisms of carcinogenesis. Although TFF3 alone may be expressed in a subset of PAC, it should be coupled with other markers (ERG, SPINK1, PTEN, high molecular weight cytokeratin) to improve the definition of molecular subtypes, the prognostic estimation, and the therapeutic decisions [33, 58].

\section{HOXB13-TFF3 associative profiles}

Association between the HOXB13 and TFF3 tissular immunoexpression has proven to be statistically significant $(p<0.0001)$. The fact that $90 \%$ (27/30) of the cases expressing strong HOXB13 immunostaining were also strongly positive for TFF3 could indicate a possible mechanism of TFF3 acting as an activated oncogene in this subset of PAC exhibiting HOXB13 overexpression, which we have found to be related to a more aggressive profile. In this regard, an experimental study has demonstrated that forced expression of TFF3 led to an increase in prostatic cellular oncogenicity, as well as in cellular migration and resistance to ionizing radiation [56].

Our data showed an increased, but not statistically significant association between high immunoexpression of HOXB13 and TFF3, respectively, and decreased biochemical recurrence free intervals. Few studies focused on the relationship of these immunomarkers and preoperatory or postoperatory PSA serum level. As far as we know, no study has been conducted addressing the combined HOXB13-TFF3 immunoexpression. Therefore, we also assessed the potential prognostic value of the different HOXB13-TFF3 subgroups of PC regarding PSA recurrence. Although we noticed a prolonged biochemical recurrence free interval in patients displaying low immunoexpression of both HOXB13 and TFF3, and a shorter one for high HOXB13-low TFF3, no statistically significant difference was proved for all four different subgroups defined by the variability of these two markers.

\section{ㅁ Conclusions}

Our results justify the role of HOXB13 and TFF3 in the stratification of PAC. High HOXB13 and TFF3 immunoexpression was commonly identified in cases characterized by a Gleason score over 7, a G4 and/or G5 dominant pattern, a grade group of 3 or 4 and a preoperatory PSA serum level over $20 \mathrm{ng} / \mathrm{mL}$. HOXB13 overexpression was also associated with pTMN stage. Four subgroups of PAC could be defined based on the differences between the IHC overexpression and low expression of HOXB13 and TFF3. Further investigations in larger cohorts are imposed to validate the clinical significance of these subgroups in the diagnostic and prognostic of PAC.

\section{Conflict of interests}

The authors declare that they have no conflict of interests.

\section{References}

[1] Bray F, Ferlay J, Soerjomataram I, Siegel RL, Torre LA, Jemal A. Global cancer statistics 2018: GLOBOCAN estimates of incidence and mortality worldwide for 36 cancers in 185 countries. CA Cancer J Clin, 2018, 68(6):394-424. https:// doi.org/10.3322/caac.21492 PMID: 30207593

[2] Rawla P. Epidemiology of prostate cancer. World J Oncol, 2019, 10(2):63-89. https://doi.org/10.14740/wjon1191 PMID: 31068988 PMCID: PMC6497009

[3] Loeb S, Bjurlin MA, Nicholson J, Tammela TL, Penson DF, Carter HB, Carroll P, Etzioni R. Overdiagnosis and overtreatment of prostate cancer. Eur Urol, 2014, 65(6):10461055. https://doi.org/10.1016/j.eururo.2013.12.062 PMID: 24439788 PMCID: PMC4113338

[4] Filella X. Towards personalized prostate cancer screening. Adv Lab Med (Avan Med Lab), 2020, 1(1):20190027. https:// doi.org/10.1515/almed-2019-0027

[5] Kaffenberger SD, Barbieri CE. Molecular subtyping of prostate cancer. Curr Opin Urol, 2016, 26(3):213-218. https://doi.org/ 10.1097/MOU.0000000000000285 PMID: 26986650 PMCID: PMC4895200 
[6] Pettersson A, Graff RE, Bauer SR, Pitt MJ, Lis RT, Stack EC Martin NE, Kunz L, Penney KL, Ligon AH, Suppan C, Flavin R, Sesso HD, Rider JR, Sweeney C, Stampfer MJ, Fiorentino M, Kantoff PW, Sanda MG, Giovannucci EL, Ding EL, Loda M, Mucci LA. The TMPRSS2:ERG rearrangement, ERG expression, and prostate cancer outcomes: a cohort study and metaanalysis. Cancer Epidemiol Biomarkers Prev, 2012, 21(9): 1497-1509. https://doi.org/10.1158/1055-9965.EPI-12-0042 PMID: 22736790 PMCID: PMC3671609

[7] Hawksworth D, Ravindranath L, Chen Y, Furusato B, Sesterhenn IA, McLeod DG, Srivastava S, Petrovics G. Overexpression of C-MYC oncogene in prostate cancer predicts biochemical recurrence. Prostate Cancer Prostatic Dis, 2010 13(4):311-315. https://doi.org/10.1038/pcan.2010.31 PMID: 20820186

[8] Xiao GQ, Unger P, Yang Q, Kinoshita Y, Singh K, McMahon L, Nastiuk K, Sha K, Krolewski J, Burstein D. Loss of PLZF expression in prostate cancer by immunohistochemistry correlates with tumor aggressiveness and metastasis. PLoS One, 2015, 10(3):e0121318. https://doi.org/10.1371/journal. pone.0121318 PMID: 25807461 PMCID: PMC4373907

[9] Geybels MS, Fang M, Wright JL, Qu X, Bibikova M, Klotzle B, Fan JB, Feng Z, Ostrander EA, Nelson PS, Stanford JL. $P T E N$ loss is associated with prostate cancer recurrence and alterations in tumor DNA methylation profiles. Oncotarget, 2017, 8(48):84338-84348. https://doi.org/10.18632/oncotarget. 20940 PMID: 29137428 PMCID: PMC5663600

[10] Ku SY, Rosario S, Wang Y, Mu P, Seshadri M, Goodrich ZW, Goodrich MM, Labbé DP, Gomez EC, Wang J, Long HW, Xu B, Brown M, Loda M, Sawyers CL, Ellis L, Goodrich DW. $R b 1$ and $\operatorname{Trp} 53$ cooperate to suppress prostate cancer lineage plasticity, metastasis, and antiandrogen resistance. Science, 2017, 355(6320):78-83. https://doi.org/10.1126/science.aah 4199 PMID: 28059767 PMCID: PMC5367887

[11] Xie Q, Wang ZA. Transcriptional regulation of the $N k \times 3.1$ gene in prostate luminal stem cell specification and cancer initiation via its 3' genomic region. J Biol Chem, 2017, 292(33): 13521-13530. https://doi.org/10.1074/jbc.M117.788315 PMID: 28679531 PMCID: PMC5566512

[12] Wu YM, Cieślik M, Lonigro RJ, Vats P, Reimers MA, Cao X, Ning Y, Wang L, Kunju LP, de Sarkar N, Heath El, Chou J, Feng FY, Nelson PS, de Bono JS, Zou W, Montgomery B, Alva A; PCF/SU2C International Prostate Cancer Dream Team, Robinson DR, Chinnaiyan AM. Inactivation of CDK12 delineates a distinct immunogenic class of advanced prostate cancer. Cell, 2018, 173(7):1770-1782. https://doi.org/10.1016/j.cell. 2018.04.034 PMID: 29906450 PMCID: PMC6084431

[13] Decker B, Ostrander EA. Dysregulation of the homeobox transcription factor gene HOXB13: role in prostate cancer. Pharmgenomics Pers Med, 2014, 7:193-201. https://doi.org/ 10.2147/PGPM.S38117 PMID: 25206306 PMCID: PMC 4157396

[14] Beebe-Dimmer JL, Hathcock M, Yee C, Okoth LA, Ewing CM, Isaacs WB, Cooney KA, Thibodeau SN. The HOXB13 G84E mutation is associated with an increased risk for prostate cancer and other malignancies. Cancer Epidemiol Biomarkers Prev, 2015, 24(9):1366-1372. https://doi.org/10.1158/1055-9965. EPI-15-0247 PMID: 26108461 PMCID: PMC4560608

[15] Ewing CM, Ray AM, Lange EM, Zuhlke KA, Robbins CM, Tembe WD, Wiley KE, Isaacs SD, Johng D, Wang Y, Bizon C, Yan G, Gielzak M, Partin AW, Shanmugam V, Izatt T, Sinari S, Craig DW, Zheng SL, Walsh PC, Montie JE, Xu J, Carpten JD, Isaacs WB, Cooney KA. Germline mutations in HOXB13 and prostate-cancer risk. N Engl J Med, 2012, 366(2):141-149. https://doi.org/10.1056/NEJMoa1110000 PMID: 22236224 PMCID: PMC3779870

[16] Lin X, Qu L, Chen Z, Xu C, Ye D, Shao Q, Wang X, Qi J, Chen Z, Zhou F, Wang M, Wang Z, He D, Wu D, Gao X, Yuan J, Wang G, Xu Y, Wang G, Dong P, Jiao Y, Yang J, Ou-Yang J, Jiang $\mathrm{H}$, Zhu Y, Ren S, Zhang Z, Yin C, Wu Q, Zheng Y, Turner AR, Tao S, Na R, Ding Q, Lu D, Shi R, Sun J Liu $F$, Zheng SL, Mo Z, Sun $Y, X u$ J. A novel germline mutation in HOXB13 is associated with prostate cancer risk in Chinese men. Prostate, 2013, 73(2):169-175. https://doi.org/ 10.1002/pros.22552 PMID: 22718278 PMCID: PMC3755486

[17] Maia S, Cardoso M, Pinto P, Pinheiro M, Santos C, Peixoto A Bento MJ, Oliveira J, Henrique R, Jerónimo C, Teixeira MR.
Identification of two novel HOXB13 germline mutations in Portuguese prostate cancer patients. PLoS One, 2015, 10(7): e0132728. https://doi.org/10.1371/journal.pone.0132728 PMID: 26176944 PMCID: PMC4503425

[18] Shang Z, Zhu S, Zhang H, Li L, Niu Y. Germline homeobox B13 (HOXB13) G84E mutation and prostate cancer risk in European descendants: a meta-analysis of 24,213 cases and 73,631 controls. Eur Urol, 2013, 64(1):173-176. https://doi.org/ 10.1016/j.eururo.2013.03.007 PMID: 23518396

[19] Kote-Jarai Z, Mikropoulos C, Leongamornlert DA, Dadaev T, Tymrakiewicz M, Saunders EJ, Jones M, Jugurnauth-Little S, Govindasami K, Guy M, Hamdy FC, Donovan JL, Neal DE, Lane JA, Dearnaley D, Wilkinson RA, Sawyer EJ, Morgan A, Antoniou AC, Eeles RA; UK Genetic Prostate Cancer Study Collaborators, and the ProtecT Study Group. Prevalence of the HOXB13 G84E germline mutation in British men and correlation with prostate cancer risk, tumour characteristics and clinical outcomes. Ann Oncol, 2015, 26(4):756-761. https:// doi.org/10.1093/annonc/mdv004 PMID: 25595936

[20] Storebjerg TM, Høyer S, Kirkegaard P, Bro F; LuCamp Study Group, Ørntoft TF, Borre M, Sørensen KD. Prevalence of the HOXB13 G84E mutation in Danish men undergoing radical prostatectomy and its correlations with prostate cancer risk and aggressiveness. BJU Int, 2016, 118(4):646-653. https:// doi.org/10.1111/bju.13416 PMID: 26779768

[21] Taupin D, Podolsky DK. Trefoil factors: initiators of mucosal healing. Nat Rev Mol Cell Biol, 2003, 4(9):721-732. Erratum in: Nat Rev Mol Cell Biol, 2003, 4(10):819. https://doi.org/10. 1038/nrm1203 PMID: 14506475

[22] Liu J, Kim SY, Shin S, Jung SH, Yim SH, Lee JY, Lee SH, Chung YJ. Overexpression of TFF3 is involved in prostate carcinogenesis via blocking mitochondria-mediated apoptosis. Exp Mol Med, 2018, 50(8):1-11. https://doi.org/10.1038/s12 276-018-0137-7 PMID: 30139961 PMCID: PMC6107499

[23] Kannan N, Kang J, Kong X, Tang J, Perry JK, Mohankumar KM, Miller LD, Liu ET, Mertani HC, Zhu T, Grandison PM, Liu DX, Lobie PE. Trefoil factor 3 is oncogenic and mediates antiestrogen resistance in human mammary carcinoma. Neoplasia, 2010, 12(12):1041-1053. https://doi.org/10.1593/neo.10916 PMID: 21170268 PMCID: PMC3003139

[24] Ahmed ARH, Griffiths AB, Tilby MT, Westley BR, May FEB. TFF3 is a normal breast epithelial protein and is associated with differentiated phenotype in early breast cancer but predisposes to invasion and metastasis in advanced disease. Am J Pathol, 2012, 180(3):904-916. https://doi.org/10.1016/ j.ajpath.2011.11.022 PMID: 22341453

[25] Huang YG, Li YF, Wang LP, Zhang Y. Aberrant expression of trefoil factor 3 is associated with colorectal carcinoma metastasis. J Cancer Res Ther, 2013, 9(3):376-380. https:// doi.org/10.4103/0973-1482.119308 PMID: 24125969

[26] May FEB, Westley BR. TFF3 is a valuable predictive biomarker of endocrine response in metastatic breast cancer. Endocr Relat Cancer, 2015, 22(3):465-479. https://doi.org/10.1530/ ERC-15-0129 PMID: 25900183 PMCID: PMC4455223

[27] Ishibashi Y, Ohtsu H, Ikemura M, Kikuchi Y, Niwa T, Nishioka K, Uchida Y, Miura H, Aikou S, Gunji T, Matsuhashi N, Ohmoto Y, Sasaki T, Seto Y, Ogawa T, Tada K, Nomura S. Serum TFF1 and TFF3 but not TFF2 are higher in women with breast cancer than in women without breast cancer. Sci Rep, 2017, 7(1):4846. https://doi.org/10.1038/s41598-017-05129-y PMID: 28687783 PMCID: PMC5501858

[28] Jahan R, Ganguly K, Smith LM, Atri P, Carmicheal J, Sheinin Y, Rachagani S, Natarajan G, Brand RE, Macha MA, Grandgenett PM, Kaur S, Batra SK. Trefoil factor(s) and CA19.9: a promising panel for early detection of pancreatic cancer. EBioMedicine, 2019, 42:375-385. https://doi.org/10.1016/j. ebiom.2019.03.056 PMID: 30956167 PMCID: PMC6491718

[29] Yusufu A, Shayimu P, Tuerdi R, Fang C, Wang F, Wang H. TFF3 and TFF1 expression levels are elevated in colorectal cancer and promote the malignant behavior of colon cancer by activating the EMT process. Int J Oncol, 2019, 55(4):789804. https://doi.org/10.3892/ijo.2019.4854 PMID: 31432157 PMCID: PMC6741840

[30] Espinoza I, Agarwal S, Reddy A, Shenoy V, Subramony C, Sakiyama M, Fair L, Poosarla T, Zhou X, Shannon Orr W, Lahr C, Bae S, Al Diffalha S, Manne U, Gomez CR. Expression of trefoil factor 3 is decreased in colorectal cancer. Oncol 
Rep, 2021, 45(1):254-264. https://doi.org/10.3892/or.2020. 7829 PMID: 33210724 PMCID: PMC7716703

[31] Faith DA, Isaacs WB, Morgan JD, Fedor HL, Hicks JL, Mangold LA, Walsh PC, Partin AW, Platz EA, Luo J, De Marzo AM. Trefoil factor 3 overexpression in prostatic carcinoma: prognostic importance using tissue microarrays. Prostate, 2004 61(3):215-227. https://doi.org/10.1002/pros.20095 PMID: 15368473 PMCID: PMC3715040

[32] Garraway IP, Seligson D, Said J, Horvath S, Reiter RE. Trefoil factor 3 is overexpressed in human prostate cancer. Prostate, 2004, 61(3):209-214. https://doi.org/10.1002/pros.20096 PMID: 15368472

[33] Terry S, Nicolaiew N, Basset V, Semprez F, Soyeux P, Maillé $P$, Vacherot F, Ploussard G, Londoño-Vallejo A, de la Taille A, Allory Y. Clinical value of ERG, TFF3, and SPINK1 for molecular subtyping of prostate cancer. Cancer, 2015, 121(9):14221430. https://doi.org/10.1002/cncr.29233 PMID: 25639219

[34] Moch H, Humphrey PA, Ulbright TM, Reuter VE (eds). World Health Organization (WHO) Classification of Tumours of the urinary system and male genital organs. $4^{\text {th }}$ edition, vol. 8, International Agency for Research on Cancer (IARC) Press, Lyon, France, 2016, 135-161. https://publications.iarc.fr/BookAnd-Report-Series/Who-Classification-Of-Tumours/WHOClassification-Of-Tumours-Of-The-Urinary-System-And-MaleGenital-Organs-2016

[35] Epstein JI, Zelefsky MJ, Sjoberg DD, Nelson JB, Egevad L, Magi-Galluzzi C, Vickers AJ, Parwani AV, Reuter VE, Fine SW, Eastham JA, Wiklund P, Han M, Reddy CA, Ciezki JP, Nyberg T, Klein EA. A contemporary prostate cancer grading system: a validated alternative to the Gleason score. Eur Urol, 2016, 69(3):428-435. https://doi.org/10.1016/j.eururo. 2015.06.046 PMID: 26166626 PMCID: PMC5002992

[36] Zeltser L, Desplan C, Heintz N. Hoxb-13: a new Hox gene in a distant region of the HOXB cluster maintains colinearity. Development, 1996, 122(8):2475-2484. PMID: 8756292

[37] Jung C, Kim RS, Lee SJ, Wang C, Jeng MH. HOXB13 homeodomain protein suppresses the growth of prostate cancer cells by the negative regulation of T-cell factor 4 Cancer Res, 2004, 64(9):3046-3051. https://doi.org/10.1158/ 0008-5472.CAN-03-2614 PMID: 15126340

[38] Jung C, Kim RS, Zhang HJ, Lee SJ, Jeng MH. HOXB13 induces growth suppression of prostate cancer cells as a repressor of hormone-activated androgen receptor signaling. Cancer Res, 2004, 64(24):9185-9192. https://doi.org/10.1158/ 0008-5472.CAN-04-1330 PMID: 15604291

[39] Kim SD, Park RY, Kim YR, Kim IJ, Kang TW, Nam KI, Ahn KY, Bae CS, Kim BY, Park SS, Jung C. HOXB13 is co-localized with androgen receptor to suppress androgen-stimulated prostate-specific antigen expression. Anat Cell Biol, 2010, 43(4):284-293. https://doi.org/10.5115/acb.2010.43.4.284 PMID 21267402 PMCID: PMC3026180

[40] Norris JD, Chang CY, Wittmann BM, Kunder RS, Cui H, Fan D, Joseph JD, McDonnell DP. The homeodomain protein HOXB13 regulates the cellular response to androgens. Mol Cell, 2009, 36(3):405-416. https://doi.org/10.1016/j.molcel.2009.10.020 PMID: 19917249 PMCID: PMC2788777

[41] McMullin RP, Mutton LN, Bieberich CJ. Hoxb13 regulatory elements mediate transgene expression during prostate organogenesis and carcinogenesis. Dev Dyn, 2009, 238(3): 664-672. https://doi.org/10.1002/dvdy.21870 PMID: 19191217 PMCID: PMC3386847

[42] Navarro HI, Goldstein AS. HoxB13 mediates $A R-V 7$ activity in prostate cancer. Proc Natl Acad Sci U S A, 2018, 115(26): 6528-6529. https://doi.org/10.1073/pnas.1808196115 PMID: 29891672 PMCID: PMC6042116

[43] Yao J, Chen Y, Nguyen DT, Thompson ZJ, Eroshkin AM, Nerlakanti N, Patel AK, Agarwal N, Teer JK, Dhillon J, Coppola D, Zhang J, Perera R, Kim Y, Mahajan K. The homeobox gene, $H O X B 13$, regulates a mitotic protein-kinase interaction network in metastatic prostate cancers. Sci Rep 2019, 9(1):9715. https://doi.org/10.1038/s41598-019-46064-4 PMID: 31273254 PMCID: PMC6609629

[44] Witte JS, Mefford J, Plummer SJ, Liu J, Cheng I, Klein EA Rybicki BA, Casey G. HOXB13 mutation and prostate cancer: studies of siblings and aggressive disease. Cancer Epidemio Biomarkers Prev, 2013, 22(4):675-680. https://doi.org/10.1158/ 1055-9965.EPI-12-1154 PMID: 23396964 PMCID: PMC 3617049
[45] Stott-Miller M, Karyadi DM, Smith T, Kwon EM, Kolb S, Stanford JL, Ostrander EA. HOXB13 mutations in a populationbased, case-control study of prostate cancer. Prostate, 2013, 73(6):634-641. https://doi.org/10.1002/pros.22604 PMID: 23129385 PMCID: PMC3612366

[46] Xu J, Lange EM, Lu L, Zheng SL, Wang Z, Thibodeau SN, Cannon-Albright LA, Teerlink CC, Camp NJ, Johnson AM, Zuhlke KA, Stanford JL, Ostrander EA, Wiley KE, Isaacs SD, Walsh PC, Maier C, Luedeke M, Vogel W, Schleutker J, Wahlfors T, Tammela T, Schaid D, McDonnell SK, DeRycke MS, Cancel-Tassin G, Cussenot O, Wiklund F, Grönberg H, Eeles R, Easton D, Kote-Jarai Z, Whittemore AS, Hsieh CL, Giles GG, Hopper JL, Severi G, Catalona WJ, Mandal D, Ledet E, Foulkes WD, Hamel N, Mahle L, Moller P, Powell I, BaileyWilson JE, Carpten JD, Seminara D, Cooney KA, Isaacs WB; International Consortium for Prostate Cancer Genetics. HOXB13 is a susceptibility gene for prostate cancer: results from the International Consortium for Prostate Cancer Genetics (ICPCG). Hum Genet, 2013, 132(1):5-14. https://doi.org/10.1007/s00 439-012-1229-4 PMID: 23064873 PMCID: PMC3535370

[47] Zabalza CV, Adam M, Burdelski C, Wilczak W, Wittmer C, Kraft S, Krech T, Steurer S, Koop C, Hube-Magg C, Graefen M, Heinzer H, Minner S, Simon R, Sauter G, Schlomm T, Tsourlakis MC. HOXB13 overexpression is an independent predictor of early PSA recurrence in prostate cancer treated by radical prostatectomy. Oncotarget, 2015, 6(14):12822-12834. https://doi.org/10.18632/oncotarget.3431 PMID: 25825985 PMCID: PMC4494977

[48] Varinot J, Cussenot $\mathrm{O}$, Roupret $\mathrm{M}$, Conort $\mathrm{P}$, Bitker MO, Chartier-Kastler E, Cheng L, Compérat E. HOXB13 is a sensitive and specific marker of prostate cells, useful in distinguishing between carcinomas of prostatic and urothelial origin. Virchows Arch, 2013, 463(6):803-809. https://doi.org/ 10.1007/s00428-013-1495-0 PMID: 24146108

[49] Cheng S, Yang S, Shi Y, Shi R, Yeh Y, Yu X. Neuroendocrine prostate cancer has distinctive, non-prostatic HOX code that is represented by the loss of HOXB13 expression. Sci Rep, 2021, 11(1):2778. https://doi.org/10.1038/s41598-021-82472-1 PMID: 33531604 PMCID: PMC7854582

[50] Jeong TO, Oh KJ, Xuan Nguyen NT, Kim YR, Kim MS, Lee SD, Ryu SB, Jung C. Evaluation of HOXB13 as a molecular marker of recurrent prostate cancer. Mol Med Rep, 2012, 5(4):901904. https://doi.org/10.3892/mmr.2012.769 PMID: 22293681 PMCID: PMC3493085

[51] Brechka H, Bhanvadia RR, VanOpstall C, Vander Griend DJ. HOXB13 mutations and binding partners in prostate development and cancer: function, clinical significance, and future directions. Genes Dis, 2017, 4(2):75-87. https://doi.org/10. 1016/j.gendis.2017.01.003 PMID: 28798948 PMCID: PMC 5548135

[52] Weiner AB, Faisal FA, Davicioni E, Karnes RJ, Griend DJV, Lotan TL, Schaeffer EM. Somatic HOXB13 expression correlates with metastatic progression in men with localized prostate cancer following radical prostatectomy. Eur Urol Oncol, 2020, Jun 12, S2588-9311(20)30055-9. https://doi.org/10.1016/j. euo.2020.05.001 PMID: 32540218 PMCID: PMC7736205

[53] Park CK, Shin SJ, Cho YA, Joo JW, Cho NH. HoxB13 expression in ductal type adenocarcinoma of prostate: clinicopathologic characteristics and its utility as potential diagnostic marker. Sci Rep, 2019, 9(1):20205. https://doi.org/10.1038/s41598019-56657-8 PMID: 31882852 PMCID: PMC6934792

[54] Kim EH, Cao D, Mahajan NP, Andriole GL, Mahajan K. ACK1$A R$ and $A R-H O X B 13$ signaling axes: epigenetic regulation of lethal prostate cancers. NAR Cancer, 2020, 2(3):zcaa018. https://doi.org/10.1093/narcan/zcaa018 PMID: 32885168 PMCID: PMC7454006

[55] Sipeky C, Gao P, Zhang Q, Wang L, Ettala O, Talala KM, Tammela TLJ, Auvinen A, Wiklund F, Wei GH, Schleutker J. Synergistic interaction of $H O X B 13$ and CIP2A predisposes to aggressive prostate cancer. Clin Cancer Res, 2018, 24(24): 6265-6276. https://doi.org/10.1158/1078-0432.CCR-18-0444 PMID: 30181389 PMCID: PMC6719560

[56] Perera O, Evans A, Pertziger M, MacDonald C, Chen H, Liu DX, Lobie PE, Perry JK. Trefoil factor 3 (TFF3) enhances the oncogenic characteristics of prostate carcinoma cells and reduces sensitivity to ionising radiation. Cancer Lett, 2015, 361(1):104-111. https://doi.org/10.1016/j.canlet.2015.02.051 PMID: 25748388 
[57] Vestergaard EM, Nexø E, Tørring N, Borre M, Ørntoft TF, Sørensen KD. Promoter hypomethylation and upregulation of trefoil factors in prostate cancer. Int $\mathrm{J}$ Cancer, 2010, 127(8):1857-1865. https://doi.org/10.1002/ijc.25209 PMID: 20112343

[58] Park K, Chiu YL, Rubin MA, Demichelis F, Mosquera JM. V-ets erythroblastosis virus $E 26$ oncogene homolog (avian)/Trefoil factor 3/high-molecular-weight cytokeratin triple immunostain: a novel tissue-based biomarker in prostate cancer with potential clinical application. Hum Pathol, 2013, 44(10):2282-2292. https://doi.org/10.1016/j.humpath.2013.05.010 PMID: 23856515

[59] Abou-Ouf H, Ghosh S, Box A, Palanisamy N, Bismar TA. Combined loss of TFF3 and PTEN is associated with lethal outcome and overall survival in men with prostate cancer.
J Cancer Res Clin Oncol, 2019, 145(7):1751-1759. https:// doi.org/10.1007/s00432-019-02933-z PMID: 31129769

[60] Vestergaard EM, Borre M, Poulsen SS, Nexø E, Tørring N. Plasma levels of trefoil factors are increased in patients with advanced prostate cancer. Clin Cancer Res, 2006, 12(3 Pt 1): 807-812. https://doi.org/10.1158/1078-0432.CCR-05-1545 PMID: 16467092

[61] Nørgaard M, Haldrup C, Storebjerg TM, Vestergaard EM, Wild PJ, Høyer S, Borre M, Ørntoft TF, Sørensen KD. Comprehensive evaluation of TFF3 promoter hypomethylation and molecular biomarker potential for prostate cancer diagnosis and prognosis. Int J Mol Sci, 2017, 18(9):2017. https://doi.org/ 10.3390/ijms18092017 PMID: 28930171 PMCID: PMC5618665

\section{Corresponding author}

Simona Eliza Giuşcă, Lecturer, MD, PhD, Department of Morphofunctional Sciences I, Grigore T. Popa University of Medicine and Pharmacy, 16 University Street, 700115 laşi, Romania; Phone +40758-383 773, e-mail: simonaelizagiusca@gmail.com

Received: January 30, 2021

Accepted: July 26, 2021 